\title{
Stenting of Extracranial Carotid Artery Stenosis
}

\author{
N. KOSHIMAE, T. MORIMOTO, K. NAGATA \\ Department of Neurosurgery Osaka police hospital
}

Key words: stenting, carotid stenosis, evaluation

\section{Summary}

The purpose of this study is to evaluate our cases of cervical internal carotid artery stenosis for safty stenting. We investigate the preoperative internal carotid artery stenosis using by integrated backscatter (IBS) method of ultra sonography, comparing with the thirty five surgical specimens as to their nature, histological structure, thickness of fibrous cap. We choose the protection method according to plaque structure, and placed Easy-Wall stent or Smart stent after prePTA. We added post PTA according to the extent of expansion and IVUS findings. Calibrated IBS = IBS value (ROI) /intinal IBS value of 'bleeding', 'lipid', 'thrombus', 'fiber', 'hyalinization' were $-27.5,-22.5,-15.2,-11.1,+2.1$. That of the thin fibrous cap were -10.9*, that of thic fibrous cap were $-2.4\left({ }^{*} p<0.001\right)$. There was a good coleration between the extent of expansion and expected histological findings. All conplications were two cases of small cerebral infarction and a case of bleeding from the complicated lung cancer. The protection at prePTA lead to no comploications in case of acute cerebral infarctions. It is very important to check the histological specimen carefully for safty stenting.

\section{Introduction}

In these days we often find asymptomatic cervical carotid lesions for spreading of non-invasive imaging, such as carotid echo, MR an-

giography. Validity of carotid endoarterectomy (CEA) has been certificated scientifically by such prospective randamized study, as North America Symptomatic Carotid Endarterectomy Trial (NASCET) or Asymptomatic Carotid Atherosclerosis Study (ACAS). But high risk cases that can not apply to any criteria of those study are often found clinically. Stenting is getting common for those cases. Cerebral infarction is most possible complication, for severe stenosis lesions are often accompanied by ulcerative changes or mural thrombus.

We analyzed the nature of stenosis by ultrasonography, and made a protection as the cases demand to good results. So we would like to report our methods.

\section{Material and Methods}

We made ultrasonic analysis to thirty five cases that had over $75 \%$ stenosis and were underwent CEA. We compared the data with thirty normal volunteers (male 15 cases, female 15 cases, average age 49 years). The analyzing targets for stenting are forty-one cases that the author had performed stenting to severe stenosis of cervical carotid artery at Osaka Police Hospital or referential hospitals till march, 2000.

\section{Ultrasonic Analysis}

We made use of SONOS 5500 (gilent Technology) for analysis. Transducer frequency was 


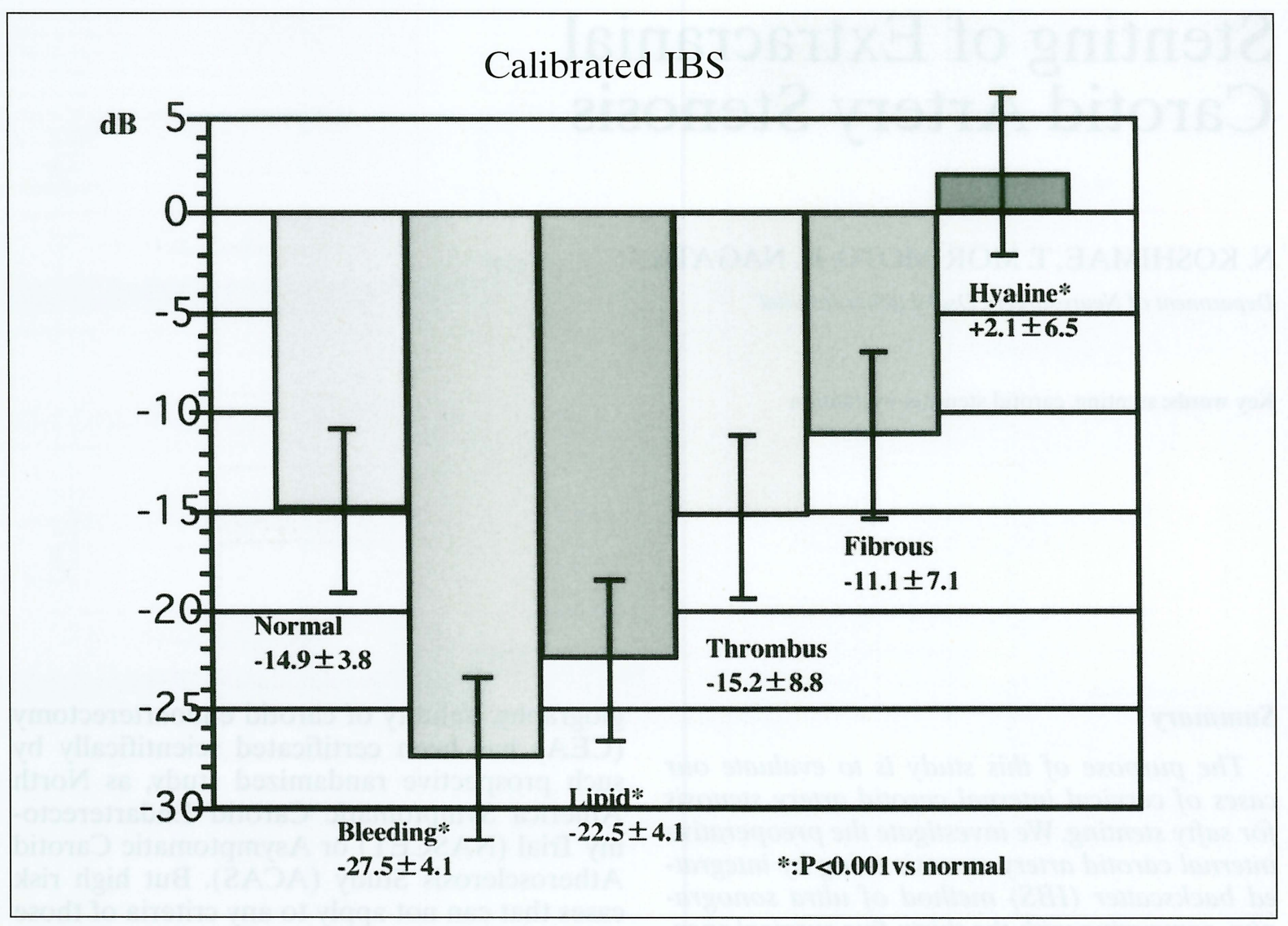

Figure 1

7.5 $\mathrm{MHz}$ linear-array transducer (axial resolution $0.1 \mathrm{~mm}$ )

We chose B-mode as ultrasonic imaging of cervical carotid, and used Integrated backscatter mothods (IBS) to examine the histological nature of the specimens. Measuring IBS value, we chose ultrasonic minor axial section that had the same plaque structure as histological specimen. We chose 'adventitia' from reference, and caluculated calibrated IBS (= IBS

\section{Table 1 Case presentation}

\begin{tabular}{|llc|}
\hline Symptomatic & & 19 \\
\hline & TIA & 11 \\
\hline & Minor stroke & 6 \\
\hline & Major stroke & 1 \\
\hline & Progressive stroke & 1 \\
\hline Asymptomatic & & 22 \\
\hline & & Total \\
\hline
\end{tabular}

value in region of interest (ROI) / IBS value of adventitia). We classified stractual elements of plaque histologically into such five groups, as 'bleeding', 'thrombus', 'lipid', 'fiber', and 'hyalinization'.

\section{Methods of Stenting}

The Way of Onset

Symptomatic cases were 19 cases, and Asymptomatic cases were 22 cases (table 1 ).

\section{Indication of Stenting}

Our indication of stenting is for a person of advanced age, high risk groups with cardialpulmonary diseases for general anesthesia, having occlusion or severe stenosis of contralateral carotid artery or high positioned carotid stenosis for CEA.

\section{Preoperative Evaluation}

We took medical history, nerological findings, and performed computed tomography 


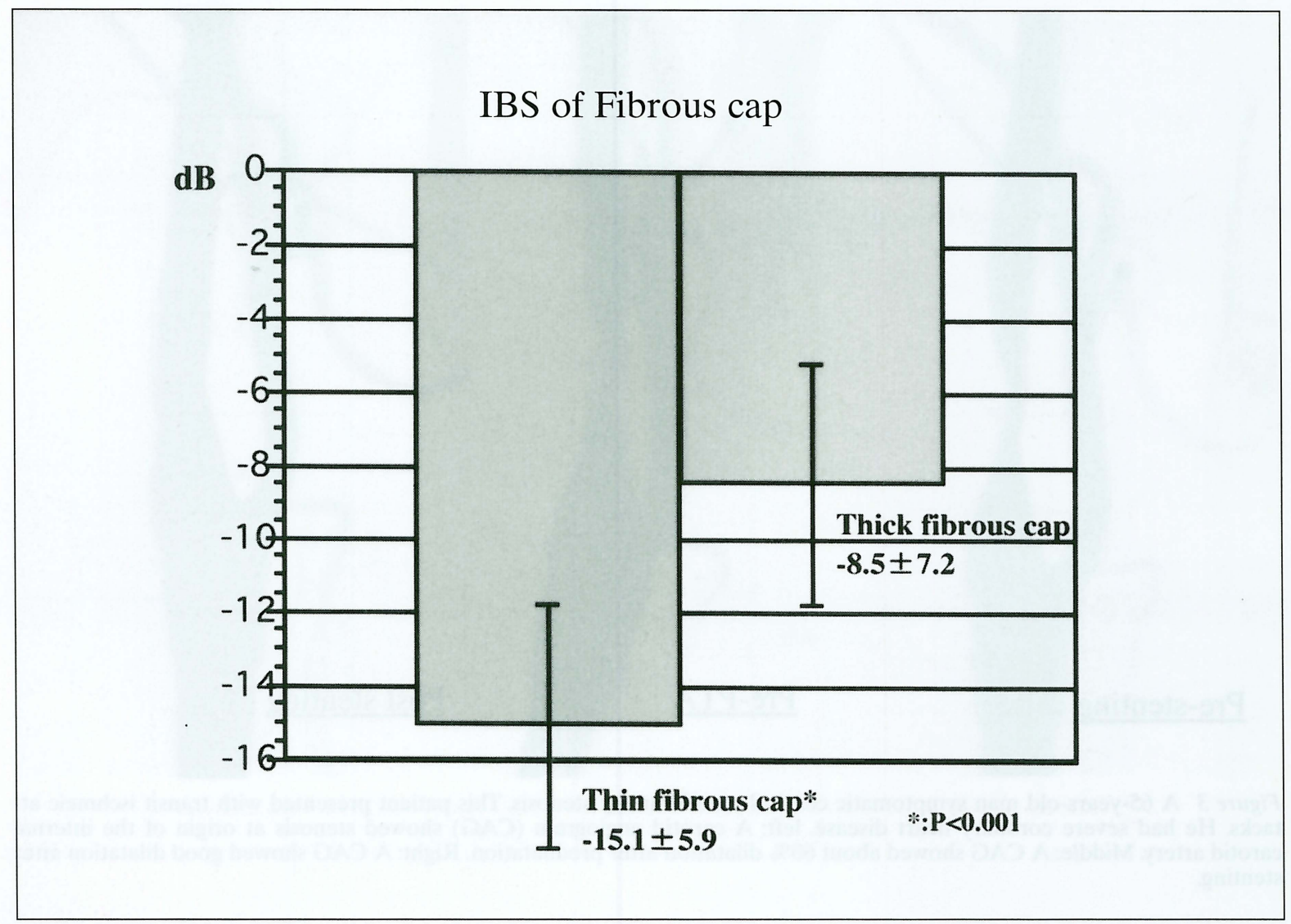

Figure 2

(CT) and magnetic resonance imaging (MRI) of brain, carotid angiography, and made an evaluation by carotid ultrasonic echography, and an evaluation of blood flow by SPECT. The stenotic ratio was calculated on NASCET basis.

\section{Procedure of Stenting}

We used self-expandable type stent; Easy Wall stent or Smart stent for stenting. Pre-expansion was performed when the stenosis was less than $2 \mathrm{~mm}$. Balloon protection at pre-expansion was needed in case of possible distal embolism from the findings of ultrasonic echography. A stent that had larger proximal diameter than stenotic segment was chosen, and it's shortning was taken into considerration.

We locate the position of stenting on DSA roadmapping. It is very important to know the stenting procedure well, for the jumping phenomenen at the time of release from catheter, and shortning of stent. Post-expansion was per- formed with PTA catheter under balloon protection, unless there had been enough expansion. Suction from proximal space of expanded carotid artery and irrigation into external carotid artery were done. We did not perform a post-expansion when we found less than $35 \%$ stenosis of residual lesion.

Table 2 Clinical presentation

\begin{tabular}{|c|}
\hline 41 Cases: male 34 , female 7 \\
\hline Age: $58 \sim 86$ y/o (average 71.3 y/o) \\
\hline Symptomatic: 19 Asymptomatic: 22 \\
\hline Total cases stenting successful \\
\hline Stenosis improvement: $87.5 \% \rightarrow 32.8 \%$ \\
\hline Mortality: $0 \%$ \\
\hline Morbidity: minor stroke 1 , lacunar infarction 2 \\
\hline Average follow-up: 9.8 mon. \\
\hline Restenosis: $1(2.4 \%)$ \\
\hline
\end{tabular}




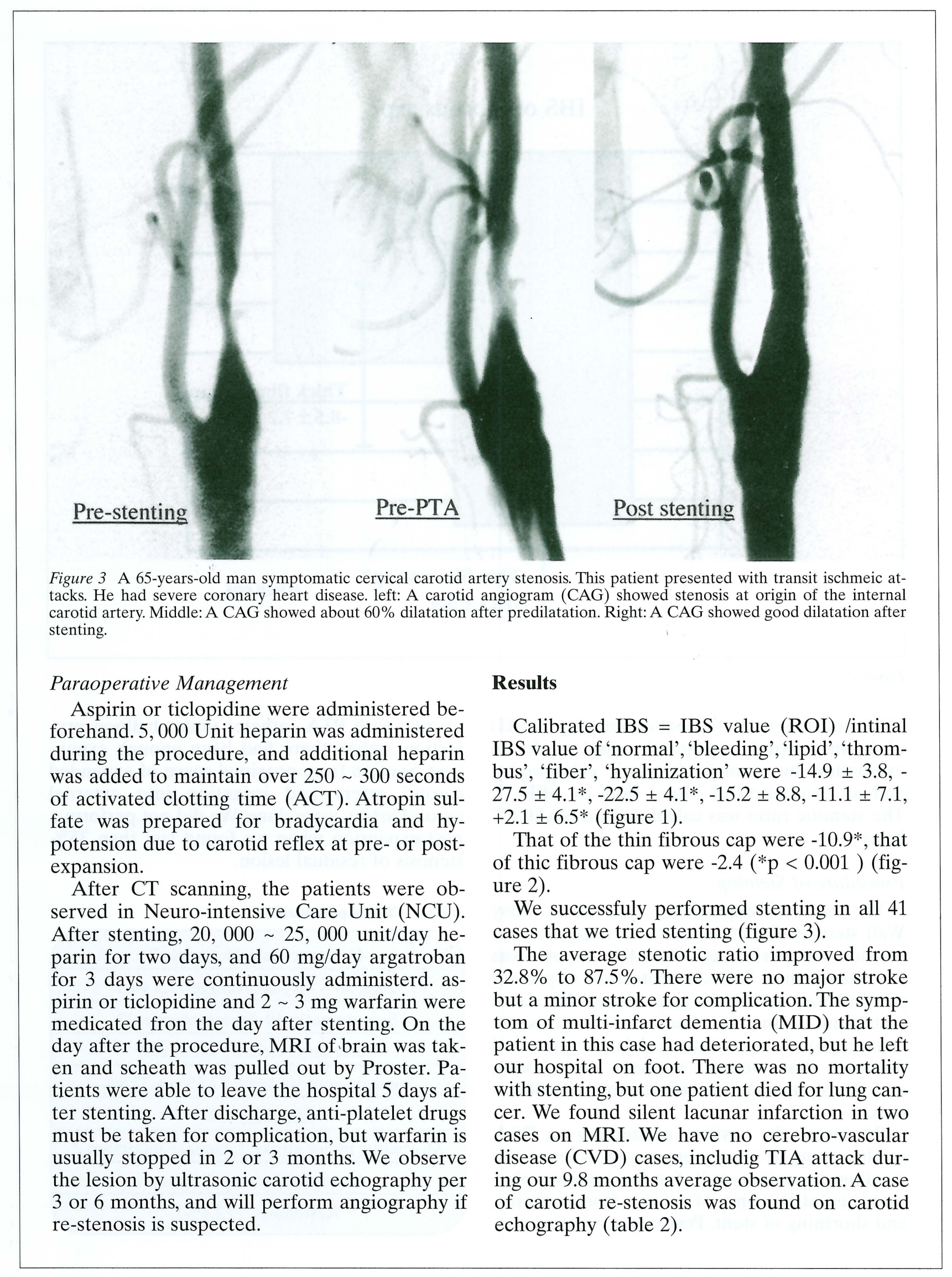




\section{Discussion}

In our study, we could know the nature of plaque, fibrous cap significantly and correctly by IBS. That is, we could know the risk of distal embolism for stenting in advance. Our results showed as follows, paraoperative mortality $0 \%$, major stroke $0 \%$, symptomatic minor stroke $2.4 \%$. Wholey reported that their success ratio of procedure $98.4 \%$, minor stroke $2.72 \%$, major stroke $1.49 \%$, mortality $0.86 \%$. We satisfied our result regardless of few number cases. We got the imformation of the lesion, performed the appropriate protection, and had good results. We approve our results because we perform the procedure on the patients who were given up for CEA.

Low pressure pre-expansion may easily cause distal enbolisms in cases of severe carotid stenosis that need stenting and had soft plaque. Only procedure of catheter is thought to be dangerous for distal embolism. This is the important reason why we try to know the nature of stenotic lesion before procedure. Anticoagulation therapy and antiplatelet therapy are necessary, but it is important to develop a new protective device that is effective, safe, and reliable. Balloon protection is used for this pur- pose now, but we hope a new device with filter that is unnecessary for blocking the flow will be in use as soon as possible.

The stenting does not have precise evidence that is effective for stroke prevention, because there are not its long term results, differing from CEA. But we have good result for stenting in spite of the fact that we performed stentitng on the patient who were out of the indication for aggressive treatment. It is necessary for us to establish the evidence on the basis of storing the long term cases from now on. Carotid Revascularization Endarterectomy vs. Stenting Trial (CREST), a prospective study between stenting and CEA is going on, so its result is expected.

\section{Conclusions}

We report our stenting for cervical carotid stenosis. Our result is not bad. The indication of treatment has extended to poor risk cases, and good result is expected. It is important for establish the safty to analyze the nature of stenotic lesion and perform an order-made treatment for each cases. Please note that only CEA has the evidence in the present state.

\section{References}

1 Albuquerque FC, Teitelbaum GP et Al: Balloon-protected carotid angioplasty. Neurosurgery 46: 918-923, 2000.

2 Deithrich EB, Ndiaye M, Reid DB: Stenting in the carotid artery: Initial experience in 110 patients. J Endovasc Surg 3: 42-62, 1996.

3 Executive Committee for the Asymptomatic carotid artery stenosis. JAMA 273: 1421-1428, 1995.

4 Nakahara I, Sakai N et Al: Stenting for Extracranial Carotid artery stenosis. Jpn J Neurosurg (Tokyo) 10: 445-453, 2001.

5 North American Symptomatic Carotid Endarterectomy Trial Collaborators: Beneficial effect of carotid endarterectomy in symptomatic patients with high-grade carotid stenosis. N Engl J Med 325: 445-453, 1991.

6 Theron J, Coutheoux P et Al: New trople coaxial catheter system for angioplasty with cerebral protection. Am J Neuroradiol 11: 869-874, 1990.
7 Theron J, Payelle GG et Al: Carotid artery stenosis: Treatment with protected balloon angioplasty and stent placement. Radiology 201: 627-636, 1996.

8 Wholey $\mathrm{MH}$, Wholey $\mathrm{M}$ et $\mathrm{Al}$ : Global experience in cervical carotid artery stent. Cathet Cardiovasc Intervent 50: 160-167, 2000. 